\title{
Uma análise preditiva para o uso do instrumento antidumping na Argentina
}

A predictive analysis for the use of antidumping in Argentina

Vinícius de Azevedo Couto Firme (1)

(1) Universidade Federal de Juiz de Fora

\section{Abstract}

This paper analyzed the influence of macroeconomic factors on the opening of antidumping cases (AD) in Argentina. The resulting model was used to predict the use of $\mathrm{AD}$ in this country. Quarterly data, from 1995 to 2010, were used to this end. The models were estimated by Ordinary Least Squares (OLS), Poisson and Negative Binominal. The results revealed that the lagged variables can cause greater impacts on the opening of $\mathrm{AD}$ cases than contemporary variables. In addition, a worsening in current account, a currency devaluation or an increase in GDP from Argentina, Brazil and the rest of the world could reduce $\mathrm{AD}$ cases. As for predictions, it was found that Poisson was the closest to the real average number of $\mathrm{AD}$ measures initiated by Argentina. However, the smaller residuals were produced by OLS estimation. In general, the predictive capability of these models reveals a misuse of $\mathrm{AD}$ from Argentina.

\section{Keywords}

antidumping; trade policy; macroeconomic variables.

JEL Codes F10; F13; F14; F15.

\section{Resumo}

Este trabalho verificou o impacto de fatores macroeconomicos sobre a abertura de casos antidumping ( $A D$ ) na Argentina e usou o modelo resultante para prever o uso do $A D$ nesse país. Para tanto, considerou dados trimestrais de 1995 a 2010. Os modelos, estimados via Mínimos Quadrados Ordinários (MQO), Poisson e Binominal Negativo, revelaram que as variáveis defasadas causam maiores impactos sobre a abertura de casos $A D$ que as variáveis contemporâneas. Além disso, uma piora nas transações correntes, uma desvalorização cambial ou um crescimento nas rendas da Argentina, do Brasil e do resto do mundo tenderiam a reduzir os casos $A D$. Quanto às previsões, verificou-se que o modelo de Poisson foi o que mais se aproximou do número real médio de medidas $A D$ iniciadas pela Argentina. Contudo, o MQO produziu os menores resíduos. De modo geral, a boa capacidade preditiva de tais modelos revela um mau uso do $A D$ por parte da Argentina.

\section{Palavras-chave}

antidumping; política comercial; variáveis macroeconômicas.

Códigos JEL F10; F13; F14; F15. 


\section{Introdução}

De acordo com a Organização Mundial do Comércio - WTO (2015), ${ }^{1}$ a Argentina foi a maior usuária de barreiras comerciais antidumping $\left(\mathrm{AD}^{2} \mathrm{da}\right.$ América Latina durante o período de 1995 a 2010. De acordo com Feinberg (2010, p. 8), o "antidumping has largely become a problem of the developing world". ${ }^{3}$ Segundo o autor, a incapacidade da Rodada Uruguai (realizada entre 1986 e 1994)de limitar o uso da prática AD por parte de países Europeus e pelos EUA acabaram aumentando o uso de medidas iniciadas por países em desenvolvimento, que, passaram a utilizar o $\mathrm{AD}$ como uma forma de retaliação aos países supracitados. $O$ autor argumenta que os 3 maiores usuários do AD em 2009 foram, respectivamente, Paquistão, Índia e Argentina. Para Firme e Vasconcelos (2013), o uso do AD na Argentina não teria paralelo. Segundo eles, esse país apresentaria a maior relação entre abertura de casos $\mathrm{AD}$ ponderada pelo PIB do mundo (isto é: $A D / P I B$ ). Em outras palavras, a Argentina utilizaria um número consideravelmente alto de medidas AD mesmo tendo uma participação tímida no PIB mundial. Esta constatação é especialmente preocupante para o Brasil, visto que, conforme revelam os dados do Ministerio de Industria - Subsecretaría de Política y Gestión Comercial da Argentina - MIND/SPGC (2011), as exportações brasileiras estão entre os principais alvos das medidas $\mathrm{AD}$ iniciadas pela Argentina (atrás apenas dos produtos chineses).

Uma vez que a Argentina é o terceiro maior destino dos produtos brasileiros (Aliceweb, 2015), ${ }^{4}$ o excesso de uso do $\mathrm{AD}$ por parte desse país pode estar inibindo as exportações de alguns setores brasileiros para a Argentina. Portanto, seria interessante entender o que leva a autoridade reguladora argentina (responsável pela abertura de casos $\mathrm{AD}$ ) a iniciar tantos processos.

\section{Sigla referente ao termo em inglês "World Trade Organization".}

2 A prática de discriminação internacional de preços por meio da fixação de preços de exportações abaixo dos preços dos produtos similares destinados ao mercado interno pela firma exportadora é comumente definida como dumping. Assim, com o intuito de reduzir ou eliminar o prejuízo causado às indústrias domésticas do país importador, a medida antidumping seria o mecanismo de correção de condutas que distorcem o comércio internacional ao serem impostas tarifas adicionais sobre as importações advindas de firmas que estariam praticando o dumping. Para obter uma taxonomia de dumping, ver WILLIG (1998).

3 Tradução própria do autor: $O$ antidumping tornou-se, em grande parte, um problema associado a economias em desenvolvimento.

4 Atrás apenas dos EUA e da China (período considerado: 1997 a 2014). 
Embora já exista algum consenso de que certas variáveis macroeconômicas (por exemplo: taxa de câmbio, renda interna e externa e saldo do balanço de pagamento) possam afetar o uso do mecanismo antidumping (Takacs, 1981; Feinberg, 1989; Leidy, 1997; Knetter;Prusa, 2003; Aggarwal, 2004; Irwin, 2005; Niels; Francois, 2006; Vandenbussche; Zanardi, 2010; Vasconcelos; Firme, 2011; Moore; Zanardi, 2011; Sudsawasd, 2012), este tipo de pesquisa ainda é considerada recente.

Além de ser uma área relativamente nova, boa parte dos estudos sobre os determinantes da abertura de casos $\mathrm{AD}$ se concentram em países com certa tradição no uso desse instrumento, como os EUA e a União Europeia. Dos trabalhos consultados, apenas Niels e Francois (2006) e Vasconcelos e Firme (2011) analisaram o uso do AD em países considerados "novos usuários". O primeiro trabalho foi aplicado ao México e o segundo ao Brasil. Portanto, o efeito de fatores macroeconômicos sobre o uso do $\mathrm{AD}$ na Argentina ainda é desconhecido. Além disso, nenhum desses trabalhos testou, empiricamente, a capacidade preditiva dos modelos.

É importante ressaltar que, segundo Firme e Vasconcelos (2015), a influência de fatores macroeconômicos, sobre a abertura de casos $\mathrm{AD}$, deslocaria o instrumento $\mathrm{AD}$ de seu objetivo principal de correção das distorções provocadas pelo comércio desleal. Desse modo, buscou-se verificar se fatores macroeconômicos poderiam afetar a abertura de casos $\mathrm{AD}$ na Argentina e se seria possível prever quantos casos $\mathrm{AD}$ seriam abertos na Argentina com base nesses fatores. Para tanto, foram realizadas regressões, via Mínimos Quadrados Ordinários (MOO), Poisson e Binomial Negativo, considerando dados trimestrais referente ao período de 1995 a 2010. De modo geral, os resultados revelaram que as variáveis defasadas causam maiores impactos sobre a abertura de casos $\mathrm{AD}$ quando comparadas às variáveis contemporâneas. Além disso, uma desvalorização cambial ou um crescimento nas rendas da Argentina, do Brasil e do resto do mundo tenderiam a reduzir o número de casos $\mathrm{AD}$. Contrariando a literatura, verificou-se que uma melhora nas transações correntes reduziria o número de casos $\mathrm{AD}$ apenas no curto prazo. Nos períodos seguintes, o número de casos aumentaria. É possível que a maior quantidade de divisas, oriunda da melhora nas transações correntes, acabe favorecendo as importações no futuro, fato que impulsionaria o número de casos antidumping. Quanto às previsões, verificou-se que o modelo de Poisson foi o que mais se aproximou do número real médio de medidas $\mathrm{AD}$ iniciadas pela Argentina. Contudo, o MQO produziu os menores resíduos. 
O restante do trabalho está organizado da seguinte forma: a seção 2 revela como o antidumping se tornou um dos principais mecanismos de proteção da atualidade. A seção 3 contém uma análise do uso do $\mathrm{AD}$ na Argentina entre 1995 e 2010. Na seção 4, apresentam-se os trabalhos que analisaram os efeitos de variáveis macroeconômicas sobre a abertura de casos $\mathrm{AD}$. A seção 5 contém os modelos econométricos e a base de dados. Por fim, têm-se os resultados, considerações finais e as referências.

\section{A difusão da prática antidumping}

Desde a criação do Acordo Geral sobre Tarifas e Comércio (GATT), ${ }^{5}$ em 1947, o mundo presenciou uma efetiva diminuição das tradicionais barreiras comerciais (Ossa, 2011). No entanto, no princípio da década de 70, um novo tipo de barreira não tarifária (BNT), denominada antidumping $(\mathrm{AD})$, valendo-se de regras obscuras, ${ }^{6}$ passou a ser largamente utilizada e se tornou objeto de discussão do GATT/OMC na Rodada Tókio, entre 1973-79 (Quinn; Slayton, 1982). A situação se agravou na década de 80 e o mecanismo AD ficou conhecido por ser o principal tipo de BNT utilizado na época. Segundo Blonigen e Prusa (2001, p. 1): "since 1980, GATT/WTO members have filed more complaints under the $A D$ statute than under all other trade laws combined, or that more $A D$ duties are now levied in any one year worldwide than were levied in the entire period 1947-1970." ${ }^{7}$

5 Que posteriormente viria a ser a Organização Mundial do Comércio (OMC).

6 Quanto ao caráter obscuro da legislação $\mathrm{AD}$, tem-se que, de acordo com Knetter e Prusa (2003), dois critérios precisam ser satisfeitos para que se caracterize a prática de dumping. Primeiro, deve haver provas de que a indústria nacional sofreu grave prejuízo devido às importações. Em segundo lugar, os produtos importados precisam ser comercializados a preços inferiores ao "valor normal" praticado no mercado interno. Como o "valor normal" é geralmente estimado de forma indireta, através do preço dos produtos exportados para outros países (the price-based method) ou via indicadores de custos de produção do país de origem (the constructed-value method), seu resultado pode ser questionável e, até mesmo, enviesado pelas autoridades reguladoras, deixando o mecanismo $\mathrm{AD}$ sujeito à pressão de grupos de interesse (formados por empresas domésticas). Nelson (2004, p. 554-555), argumentando sobre este mecanismo, releva que: "It is, instead, about protection and, both because it wraps itself in the mantle of fairness and because it is obscure and because its details permit greater protection to be delivered than would be the case with simple legislated protection, antidumping protection is particularly bad protection". Segundo Evenett (2006, p. 733): "An important feature of the implementation of anti-dumping laws is that there is considerable room for discretion by administering officials. (...) This is not to suggest that officials are breaking the law, rather that they may be using the discretion available to them to respond to incentives to supply protection to influential domestic interests and constituencies." 
Este cenário levou as medidas $\mathrm{AD}$ de volta à mesa de discussões do GATT/OMC durante a rodada Uruguai (1986-1994). Prusa (1999) revela que estes encontros foram marcados pela oposição entre países considerados "tradicionais usuários" da prática $\mathrm{AD}$ (liderados pelos EUA e União Europeia) e os "não tradicionais". Devido aos esforços dos EUA e da Comunidade Europeia, não foi possível restringir o uso do recurso $\mathrm{AD}$. Fato que acabou impulsionando a utilização desse mecanismo. Segundo Zanardi (2004), esta expansão ocorreu tanto entre os "tradicionais usuários" do $\mathrm{AD}$ (como Estados Unidos, Canadá, Comunidade Europeia, Austrália e Nova Zelândia), ${ }^{8}$ quanto por países como México, Brasil, Argentina, África do Sul, entre outros países sem tradição no uso deste instrumento.

Miranda (2003) argumenta que o grande volume de casos AD registrados nos anos 80 e 90 foi um retrocesso no processo de liberalização comercial. Para Blonigen e Prusa (2001, p. 3), o AD é, na atualidade, "simplesmente uma moderna forma de protecionismo". O uso excessivo de tal recurso tem levado os estudiosos do comércio internacional a mudar o foco das convencionais medidas de proteção comercial para a análise dos efeitos de medidas AD (Staiger; Wolak, 1994; Prusa, 1996 e 1999; Konings; Vandenbussche; Springael, 1999; Zanardi, 2004; Firme; Vasconcelos, 2012).

No entanto, uma questão ainda em aberto refere-se à influência de fatores macroeconômicos, tais como a taxa real de câmbio e o nível de atividade econômica interna e externa sobre a abertura de casos $\mathrm{AD}$. Nesse caso, a prática $\mathrm{AD}$ se tornaria apenas uma ferramenta de política econômica, deslocando-se, assim, de seu objetivo principal de correção das distorções provocadas pelo comércio desleal (Feinberg, 1989 e 2005; Leidy, 1997; Becker e Theuringer, 2001; Knetter e Prusa, 2003; AggarwaL, 2004; Niels; Francois, 2006; Vasconcelos; Firme, 2011). Desse modo, buscou-se verificar se fatores macroeconômicos poderiam afetar a abertura de casos $\mathrm{AD}$ na Argentina e se seria possível prever quantos casos $\mathrm{AD}$ seriam abertos na Argentina com base nesses fatores.

7 Tradução própria do autor: Desde 1980, os membros do GATT/OMC apresentaram mais queixas sob o regime antidumping $(A D)$ do que sob todas as outras medidas de proteção comercial combinadas, ou que, atualmente, mais direitos $A D$ são impostos em um único ano, no mundo, do que em todo o período 1947-1970.

8 Trebilcock e Howse (2002) disponibilizam uma visão histórica da evolução da legislação antidumping junto ao GATT e à legislação interna do Canadá, dos Estados Unidos e da Comunidade Europeia. 


\section{A utilização do mecanismo antidumping na Argentina}

No intuito de analisar o que determina a abertura de casos $\mathrm{AD}$ na Argentina, torna-se importante entender como esse instrumento é utilizado no país e o tempo necessário para que um pedido de proteção $\mathrm{AD}$, realizado por uma empresa qualquer, seja aberto pela autoridade reguladora.

$\mathrm{Na}$ Argentina, os produtores que se sentem lesados pelas importações em concorrência desleal (dumping e subsídios) devem procurar a Diretoria de Concorrência Desleal - DCD (órgão da Subsecretária de Políticas e Gestão Comercial - SPGC) que, em conjunto com a Comissão Nacional de Comércio Exterior - CNCE, irá julgar o caso.

Em resumo, a SPGC tem 220 dias e a CNCE 250 dias, a partir da abertura do processo, para determinar uma medida definitiva, alegando a existência (ou não) de dumping (alçada da SPGC) e dano à indústria nacional (analisado pela CNCE). Feito isto, a SPGC tem 10 dias para indicar à Secretária de Indústria e comércio (SIC) a determinação julgada. Já a SIC tem 10 dias para expedir um relatório para o Ministério da Produção recomendando a medida a ser adotada. $\bigcirc$ Ministério tem 20 dias para decidir sobre o processo. Toda a investigação deveria ser realizada em 10 meses. Porém, esse período nem sempre é respeitado (MIND/SPGC, 2011).

Analisando os relatórios semestrais do MIND/SPGC (2011) sobre abertura de casos $\mathrm{AD}$, é possível verificar que, em boa parte deles, os indícios de dumping e dano consideram períodos anteriores a 2 anos (contados a partir da abertura do processo). ${ }^{9}$

Portanto, as investigações $\mathrm{AD}$ na Argentina poderiam ser afetadas por fatores que ocorreram há mais de 2 anos. A ideia de que variáveis defasadas influenciariam o uso do $\mathrm{AD}$ já havia sido destacada por Knetter e Prusa (2003). Segundo os autores, seria plausível considerar uma defasagem de um a três anos. ${ }^{10}$ Para Aggarwal (2004), um ano já seria suficiente. ${ }^{11}$

9 Cabe ressaltar que o MIND/SPGC (2011) passou a divulgar a investigação para dano e dumping no período de pré-abertura do processo apenas a partir do relatório referente ao $1^{\circ}$ semestre de 2009. Nos relatórios anteriores, esta informação não está disponível.

10 "While not specified under WTO rules, all of the reporting countries generally analyze pricing behavior over the year prior to the filing of the case in order to assess LTFV [less than fair value]. By contrast, all of the reporting countries evaluate injury over a longer time horizon. In general, injury is determined over the three years preceding the filing. Given these features of the law, it seems plausible to consider lags from one to three years for our variables" (Knetter \& Prusa, 2003, p. 9).

11 "As a matter of practice, the industry must be suffering material injury during the investigation period and detailed injury margin calculations are based on the data existing during this period which 
Sendo assim, este trabalho considerou um período de 2 anos de defasagem (8 trimestres).

Quanto ao uso do antidumping na Argentina, observou-se que 326 processos de investigação de dumping foram abertos entre julho de 1995 e junho de 2010. Do total, 59,5\% obtiveram como resultado a aplicação do direito antidumping e 29,1\% ficaram sem aplicação. Apenas 7,4\% dos casos encerraram com compromissos de preços (Tabela 1). ${ }^{12}$

Tabela 1 Investigações antidumping na Argentina - julho de 1995 a junho de 2010

\begin{tabular}{|c|c|c|c|c|c|}
\hline Período & Abertura & $\begin{array}{r}\text { Medida } \\
\text { Provisória }\end{array}$ & $\begin{array}{r}\text { Direito } \\
\text { Definitivo }\end{array}$ & $\begin{array}{r}\text { Compro- } \\
\text { missos de } \\
\text { Preços }\end{array}$ & $\begin{array}{r}\text { Sem } \\
\text { Aplicação de } \\
\text { Medidas }\end{array}$ \\
\hline $07 / 1995$ a $12 / 2000$ & 147 & 35 & 63 & 7 & 56 \\
\hline $01 / 2001$ a $12 / 2005$ & 81 & 50 & 69 & 9 & 20 \\
\hline $01 / 2006$ a 06/2010 & 98 & 41 & 62 & 8 & 19 \\
\hline Total & 326 & 126 & 194 & 24 & 95 \\
\hline $\begin{array}{l}\% \text { sobre o } \\
\text { Total de Abertura }\end{array}$ & 100 & 38,7 & 59,5 & 7,4 & 29,1 \\
\hline
\end{tabular}

Fonte: Elaboração própria com base no MIND/SPGC (2011).

Tal resultado não fica distante de seu vizinho, o Brasil, principalmente no que se refere ao percentual de casos que encerram com aplicação de direito antidumping. Vasconcelos e Firme (2011), ao analisar o caso brasileiro entre 1988 e 2007, concluíram que 55\% dos casos obtiveram como resultado a aplicação do direito antidumping, $41 \%$ ficaram sem aplicação do direito e $4 \%$ obtiveram com compromissos de preços.

Esses resultados também se assemelham à experiência mundial. Segundo Zanardi (2004), a média mundial de aplicação de direito $\mathrm{AD}$, decorrentes de investigações de dumping, ficou em torno de $56 \%$ para o período de 1981 a 2001. Contudo, verificou-se uma grande dispersão dos resultados entre os "tradicionais usuários" do AD. A Comunidade Europeia, por exemplo, aplicou medidas $\mathrm{AD}$, com imposição de tarifas, em $74 \%$ dos casos investigados entre 1981 a 2001, enquanto os Estados Unidos aplicaram

is 1 year preceding the AD application. It was therefore decided to use the regressors with 1-year lag" (AggarwaL, 2004, p. 1048).

12 Caso em que as empresas estrangeiras citadas nos processos de investigação de dumping voluntariamente acordam em alterar seus preços. 
medidas $\mathrm{AD}$ em $59 \%$ dos processos. No caso da Austrália, Canadá e Nova Zelândia, esta taxa foi de $41 \%, 58 \%$ e $48 \%$, respectivamente (Zanardi, 2004, p.424-425).

No que se refere à discriminação dos casos $\mathrm{AD}$, iniciados pela Argentina entre julho de 1995 e junho de 2010, por país-alvo, percebe-se que o Brasil e a China são alvos de quase metade dos casos. Nesse período, a Argentina abriu 58 casos contra empresas brasileiras e 91 contra empresas chinesas (Gráfico 1). Isso representa, respectivamente, 18\% e 28\% do total de casos abertos para investigação no período analisado (Gráfico 2).

Gráfico 1 Casos antidumping abertos na Argentina por país investigado

(Valor acumulado entre 1995 e 2010)

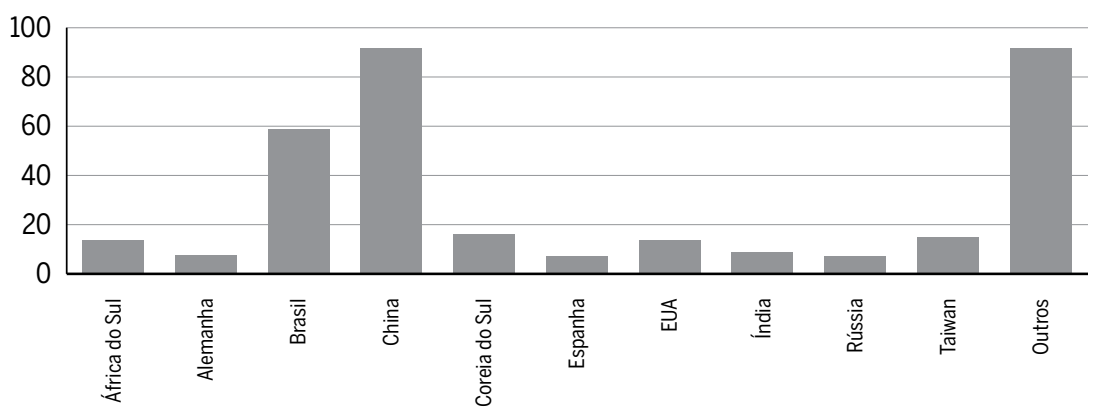

Número de Medidas Abertas para Investigação

Fonte: Elaboração própria com base nos dados do MIND/SSPGE (2011).

Gráfico 2 Casos antidumping abertos na Argentina por país investigado

(Percentual acumulado entre 1995 e 2010)

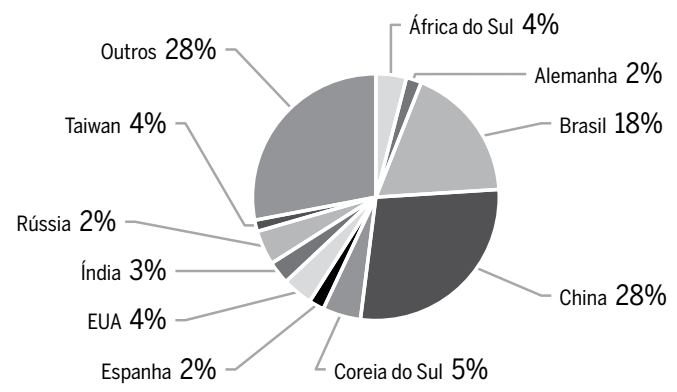

Fonte: Elaboração própria com base nos dados do MIND/SSPGE (2011). 
A análise da abertura anual de casos $\mathrm{AD}$ na Argentina, discriminada pelos principais países alvos dessas medidas, revelou que 2000 foi o ano com o maior número de casos. Somente neste ano foram abertas 44 investigações $\mathrm{AD}$. Isso se deveu pouco à maior incidência de casos contra o Brasil e a China, e sim à elevação na abertura contra os demais países. Nos anos seguintes, os casos $\mathrm{AD}$ reduzem e depois voltam a aumentar consideravelmente entre 2008 e 2009 (Gráfico 3).

\section{Gráfico 3 Evolução anual dos casos antidumping iniciados pela Argentina contra o Brasil, a China e os demais países (1995 a 2010)}

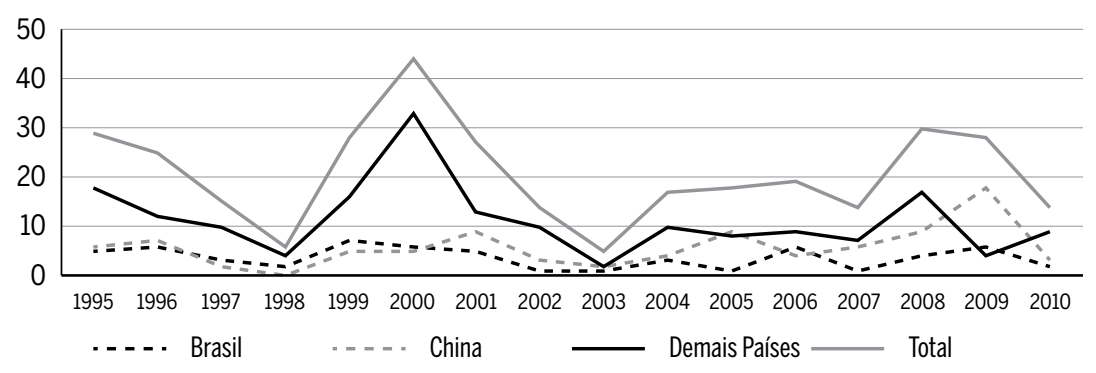

Fonte: Elaboração própria do autor com base no MIND/SPGC (2011).

A literatura ainda não entende completamente os fatores que geram oscilações no número de casos AD. No entanto, Ahn e Shin (2011), ao analisarem o número de casos iniciados entre 1995 e 2009, argumentam que "the overall trend of $A D$ investigations clearly shows the counter-cyclical movement that the increases of $A D$ investigations during the early and the late 2000s have coincided with global economic recession" ${ }^{13}$ Isso explicaria o crescimento no número de casos verificados em 2008 e 2009, visto que esses anos marcaram a crise do setor imobiliário americano, que se espalhou pelo mundo gerando reflexos negativos na atividade econômica de diversos países. Além disso, Bown (2011) também defende que o uso dos principais mecanismos de proteção comercial (que incluem o antidumping) frequentemente aumenta durante períodos de crise. $O$ autor observou este fenômeno nas crises de 1990-1991, 1997-1998 e 2001-2002. No caso específico da Argentina, o elevado número de casos $\mathrm{AD}$ em 2000, seguido de uma diminuição nos anos

13 Tradução própria do autor: a tendência associada às investigações $A D$ revela um movimento anticíclico (com o desempenho econômico). De modo geral, verificou-se que o crescimento das investigações $A D$, no início e no final da década de 2000, coincidiu com períodos onde houve recessão econômica mundial. 
seguintes, pode estar associado à diminuição das reservas internacionais argentinas nesse período. ${ }^{14}$ Fato que culminou com uma maxidesvalorização do câmbio argentino, no final de 2001, marcando o fim da paridade entre o Peso Argentino e o Dólar. ${ }^{15}$

Observando o Gráfico 3, nota-se ainda que o número de processos abertos contra o Brasil e a China vinham apresentando trajetórias semelhantes até o ano 2000. Após esse ano, o número de casos contra a China cresceu e, com exceção de 2006, foi superior ao do Brasil até o final da amostra. Esta elevação no uso do $\mathrm{AD}$ contra a China segue o padrão internacional e pode se dever à maior inserção de produtos chineses no mercado. Segundo Amiti e Freund (2008, p. 2): "China's real exports increased by more than 500 percent over the last 15 years." ${ }^{16}{ }^{17}$ Logo, é possível que a massiva entrada destes produtos no mercado internacional tenha contribuído para a elevação dos casos AD contra a China.

\section{0 efeito de fatores macroeconômicos sobre a aber- tura de casos antidumping}

Segundo Niels e Francois (2006), existem trabalhos, realizados principalmente para os EUA e União Europeia, que comprovam que as medidas antidumping podem ser influenciadas por variáveis macroeconômicas. Em parte, isso ocorreria devido à pressão protecionista (contrária à importação de produtos estrangeiros) que geralmente ocorre em períodos de recessão ou apreciação cambial. Takacs (1981) foi um dos primeiros a encontrar evidências empíricas sobre essa relação. ${ }^{18}$ Posteriormente, Leidy

14 Segundo Niels e Francois (2006), déficits em transações correntes tendem a aumentar a pressão por proteção comercial.

15 Maiores detalhes sobre o fim da âncora cambial argentina e a crise vivenciada pelo país nesse período podem ser encontrados em Bello (2002) e Batista Jr. (2002).

16 Tradução própria do autor: As exportações reais da China aumentaram em mais de 500\% nos últimos 15 anos.

17 De acordo com esses autores, a explicação do fenômeno seria decorrente de uma forte mudança na estrutura de exportação chinesa - "China's export structure has transformed dramatically since 1992."

18 O fato de o mecanismo antidumping ter se popularizado apenas na década de 80 faz com que trabalhos anteriores a este período sejam raros. Conforme relembra Aggarwal (2004, p. 1044): "Antidumping disputes were relatively few and far between until 1980. There is no exact accounting of worldwide AD activity for this period because before 1980, GATT did not require countries to report their contingent protection actions". 
(1997) comprovou que o número de medidas antidumping e compensatória ${ }^{19}$ aumentou nos EUA com o crescimento do desemprego e a diminuição da utilização da capacidade instalada da indústria. Além disso, o autor verificou a influência da variação real do dólar sobre o número de medidas antidumping para os EUA e encontrou uma relação positiva. Logo, uma valorização do dólar levava a um crescimento de processos antidumping. Resultado semelhante também foi encontrado por Irwin (2005) ao analisar o mesmo país entre 1947 e 2002. Todavia, Feinberg (1989), analisando a economia dos EUA entre 1982 e 1987, encontrou uma relação contrária entre a valorização do dólar e o número de processos antidumping. Em estudo mais recente, utilizando dados das EUA, União Europeia, Austrália e Canadá para o período de 1980 e 1998, Knetter e Prusa (2003) concluíram que a apreciação do câmbio real e a diminuição do PIB real tendem a aumentar as reclamações antidumping.

Boa parte da literatura sobre o tema reconhece a existência de uma relação inversa entre crescimento econômico e a abertura de processos $\mathrm{AD}$. Conforme ressalta Aggarwal (2004), a probabilidade de comprovação de dano à indústria doméstica aumentaria em momentos de crise. ${ }^{20}$ Além disso, uma desaceleração na atividade econômica poderia induzir as firmas estrangeiras a reduzir seus preços a fim de manter o mercado, o que facilitaria a constatação de dumping por meio do critério de preço abaixo do valor normal. ${ }^{21}$

Quanto ao impacto da taxa de câmbio real, Knetter e Prusa (2003) argumentam que ela poderia, em termos teóricos, tanto aumentar quanto diminuir o número de aplicações do direito antidumping. De um lado, a elevação no volume de importações gerada por uma apreciação da moeda doméstica poderia aumentar a probabilidade de se concluir por aplicar o direito antidumping através do critério de dano material. Alternativamente, a apreciação da moeda doméstica dificultaria a comprovação de dumping segundo o critério do preço-base. ${ }^{22}$

19 Que visa compensar o efeito de um subsídio danoso ao comércio.

20 "If the macroeconomic environment is sluggish, any import competition may put further downward pressure on the capacity utilization, profit margins and employment. Moreover, under such circumstances, the probability of an affirmative material injury finding also increases." (Aggarwal, 2004, p. 1047). 21 "A weak economy in the importing country might naturally lead foreign firms to reduce prices on shipments to the importing country. This could increase the likelihood of pricing below fair value." (Knetter; Prusa, 2003, p. 2).

22 Quando o preço de um bem exportado do país "x" para o país "y" está abaixo do preço que o país " $x$ " cobra de outros mercados (que também importam o mesmo produto do país "x"). 
O nível de atividade econômica externa também apresenta um caráter ambíguo. Neste caso, um cenário recessivo internacional dificultaria a determinação de dumping pelo argumento do preço abaixo do valor justo. O fato é que uma recessão externa causaria uma redução generalizada nos preços dos produtos exportados e não apenas àqueles que têm como destino o país doméstico em questão. Entretanto, aumentaria a probabilidade de confirmação de dumping via dano material às firmas domésticas, visto que a maior oferta de exportação, com a finalidade de escoar a produção dos países exportadores diminuiria não apenas os preços externos, mas também a lucratividade das firmas domésticas (Knetter; Prusa, 2003).

O saldo do balanço de pagamentos (BP) ou das Transações Correntes (TC) também poderia influenciar a abertura de casos AD. Segundo Niels e Francois (2006, p. 393), "Political pressure for trade protection is likely to increase with the size of the current account deficit". Aggarwal (2004, p. 1053) argumenta que "External pressures such as import penetration and balance of payment deficits also exert a considerable influence on the use of $A D$ ". Moore e Zanardi (2011) e Sudsawasd (2012) também reconhecem que estas variáveis poderiam afetar o número de processos $\mathrm{AD}$. Desta forma, um déficit no BP ou em TC aumentaria tanto a procura por proteção por parte das firmas domésticas quanto à probabilidade de que o processo $\mathrm{AD}$ venha a ser aceito pela unidade reguladora.

No caso de países considerados novos usuários do regime antidumping, há o estudo de Niels e Francois (2006), que investiga a relação entre fatores macroeconômicos e pedidos de investigação de dumping para o México. Considerando o período de 1987 a 2000, os autores concluem que há evidências de que a apreciação da taxa de câmbio real e uma piora na balança comercial acarretariam em aumento dos processos antidumping. Com relação ao nível de atividade econômica interna e externa, encontrou-se uma relação negativa com as petições antidumping. Assim, em cenários recessivos aumentaria a pressão por proteção antidumping.

Embora o trabalho de Niels e Francois (2006) indique que variáveis macroeconômicas influenciam a abertura de casos $\mathrm{AD}$, o estudo de Vasconcelos e Firme (2011), realizado para o Brasil, aponta na direção contrária. Os resultados obtidos por esses autores revelam que variáveis macroeconômicas não têm efeito sobre o número de processos de investigação abertos entre 1990-2007. Assim, a autoridade brasileira não se deixaria influenciar por oscilações econômicas no momento de decidir pela abertura de um processo $\mathrm{AD}$. 
Aggarwal (2004) também investigou o efeito de fatores macroeconômicos sobre o uso do mecanismo antidumping. Para tanto, o autor preferiu utilizar dados em painel contendo informações de 99 países entre os anos de 1980 e 2000. Seus resultados indicam que o nível de atividade econômica afeta tanto o número de petições de investigações quanto o resultado dessas investigações. ${ }^{23}$ Além disso, o autor revela que países desenvolvidos estariam utilizando esse instrumento mais como uma ferramenta protecionista do que como um mecanismo de correção do comércio desleal. Enquanto isso, os países em desenvolvimento estariam concentrando este recurso na retaliação ao uso do mecanismo por parte de países estrangeiros.

Os trabalhos analisados revelam que o número de investigações antidumping $(N I)$, iniciadas por um país, podem ser afetadas por oscilações $(\Delta)$ na Atividade Econômica Interna $(Y)$ e Externa $\left(Y^{*}\right)$, na Taxa de Câmbio real $(E)$ e no saldo do Balanço de Pagamentos ou das transações correntes (TC). ${ }^{24}$ Devido ao elevado número de instigações AD contra o Brasil, optou-se por desagregar a atividade econômica externa em renda do Brasil $\left(Y^{B R A}\right)$ e renda do resto do mundo $\left(Y^{*}\right) .{ }^{25}$ Sendo este último com Brasil e Argentina excluídos. Formalmente:

$$
N I=f\left(\Delta Y, \Delta Y^{*}, \Delta Y^{B R A}, \Delta E, \Delta T C\right)
$$

Logo, um modelo econométrico foi utilizado (ver seção 5) no intuito de testar se tais fatores poderiam afetar a unidade regulada da Argentina.

\section{Modelo econométrico}

Procurando verificar se fatores macroeconômicos, como taxa de câmbio, nível de atividade interna e externa e saldo em transações correntes, influenciaram a abertura de processos antidumping na Argentina entre julho de 1995 a junho de 2010, empregou-se um modelo de defasagem distribuída semelhante àquele proposto por Niels e Francois (2006) e Vasconcelos e

23 Outros trabalhos que analisam os efeitos variáveis macroeconômicos sobre a decisão da unidade reguladora em aplicar antidumping, ver: Finger et al. (1982), Hansen e Prusa (1997), Feinberg (2005) e Francois e Niels (2004).

24 Nesta pesquisa, optou-se pelo uso do saldo em transações correntes.

25 Espera-se que, deste modo, seja possível testar se a atividade econômica brasileira exerce influência sobre o número de casos $\mathrm{AD}$ na Argentina. 
Firme (2011). Conforme mencionado na seção 3, optou-se por utilizar uma defasagem de 2 anos (8 trimestres) para cada variável.

Com relação aos modelos de defasagem distribuída, Greene (1997) argumenta que é possível reconhecer que qualquer variação nas variáveis explicativas pode gerar efeitos para além do seu próprio período de tempo. Assim, as consequências das oscilações econômicas podem perdurar ao longo do tempo ${ }^{26}$ Portanto, trata-se de um modelo dinâmico que leva em consideração a possibilidade de efeitos defasados por parte das variáveis explicativas, conforme demonstrado na Equação 2.

$$
y_{t}=a+\beta_{0} X_{t}+\beta_{1} X_{t-1}+\ldots+\beta_{k} X_{t-k}+\varepsilon
$$

em que: $y$ é a variável dependente; a é uma constante do modelo; $X$ é uma matriz de variáveis explicativas. $\beta_{0}, \beta_{1} \ldots \beta_{k}$ são parâmetros que acompanham $X ; \varepsilon$ é um termo de erro aleatório $\left[N \sim\left(0, S^{2}\right)\right]$. Por fim, o termo subscrito representa o período $t$ e suas defasagens $t-1, \ldots, t-k$;

Substituindo os elementos da expressão 1 na equação 2, de modo que $y=N I$ e $X=\left[\Delta Y, \Delta Y^{*}, \Delta Y^{B R A}, \Delta E, \Delta T C\right]$, é possível obter o modelo básico estimado neste trabalho. ${ }^{27}$

Note que, em se tratando de análise econômica, as relações de dependência entre variáveis nem sempre são instantâneas. Em muitos casos, $y$ responde a variações em $X$ com certo atraso (ou defasagem). Felizmente, o modelo descrito na Equação 2 é capaz de mensurar tal efeito ao longo do tempo. Deste modo, tem-se que $\beta_{0}$ seria o coeficiente de impacto ou multiplicador de curto prazo, visto que uma variação em alguma variável $X_{t}$ causa um efeito contemporâneo em $Y_{t}$. Portanto, $\beta_{0}$ seria a derivada parcial de $Y_{t}$, em relação a $X_{t}$, enquanto $\beta_{1}$ seria a derivada parcial em relação a $X_{t-1}$ e assim por diante. Se uma mudança unitária em $X$ é mantida, $\left(\beta_{0}+\beta_{1}\right)$, medem o impacto em $Y$ no próximo período, $\left(\beta_{0}+\beta_{1}+\beta_{2}\right)$ no período seguinte, e assim por diante. Essa soma parcial é denominada impacto intermediário. Finalmente, após $k$ períodos de tempo, obtém-se o

26 Esta informação pode ser importante para os formuladores de políticas econômicas, pois é possível mensurar quanto da modificação acontecerá no instante em que ela ocorre e quanto ocorrerá nos períodos seguintes.

27 Assim como Knetter e Prusa (2003) e Aggarwal (2004), todas as variáveis explicativas foram utilizadas em diferenças. Então, as variáveis explicativas denominadas "contemporâneas" (e.g.: $\left.\Delta X_{t}\right)$ são, na realidade, o $\ln \left(X_{t} / X_{t_{-1}}\right)$, enquanto o $\ln \left(X_{t_{-1}} / X_{t_{-2}}\right)$, representaria a primeira defasagem (e.g.: $\left.\Delta X_{t-1}\right)$ e assim por diante. 
impacto de longo prazo, ou impacto total, que é dado pela soma dos betas, $\beta$. A divisão de cada beta $\left(\beta_{t-k}\right)$ pelo beta total $(\beta)$ permite mensurar o efeito relativo, em valores percentuais, da variável explicativa a cada período.

É importante ressaltar que, como o número de investigação antidumping (NI) apresenta características de uma variável de contagem (ou seja, assume um número reduzido de valores inteiros e não negativos), a estimação via Mínimos Quadrados Ordinários (MQO) pode ficar comprometida. O fato é que este tipo de variável não deve ser tratada como contínua e dificilmente apresentará uma distribuição normal. Segundo Greene (2002, p. 740),

In principle, we could analyze these data using multiple linear regression. But the preponderance of zeros and the small values and clearly discrete nature of the dependent variable suggest that we can improve on least squares and the linear model with a specification that accounts for these characteristics. The Poisson regression model has been widely used to study such data. ${ }^{28}$

A função de densidade condicional de $y_{i}$, dado os $X_{i}$ regressores, via Poisson é:

$$
f\left(y_{i} \mid X_{i}^{\prime} \beta\right)=\left[e^{-\exp \left(X_{i}^{\prime} \beta\right)} \exp \left(X_{i}^{\prime} \beta\right)^{y_{i}}\right] / y_{i} !
$$

em que: $y_{i}$ é a variável dependente, composta por valores inteiros não negativos $\{0,1.2 \ldots\} ; X_{i}$ é uma matriz contendo as variáveis explicativas e $\beta$ são os parâmetros associados à tais variáveis.

A equação 3 revela que o modelo não é linear em seus parâmetros. Sendo assim, os modelos de regressão linear não seriam capazes de fornecer boas estimativas. Conforme relembra Wooldridge (2002, cap. 12), uma alternativa seria a utilização dos Mínimos Quadrados Não-Lineares. Contudo, o autor argumenta que tal abordagem não explora a heterocedasticidade que geralmente acompanha os dados de contagem. Assim, a estimação por máxima verossimilhança apresenta melhores resultados.

De acordo com Greene (2002), o estimador de máxima verossimilhança (EMV), oriundo da equação 3, pode ser calculado por meio da maximização da função de Log-Verossimilhança:

28 Tradução própria do autor: A princípio, poderíamos analisar esses dados usando uma regressão linear múltipla. Contudo, a preponderância de zeros e de valores pequenos, somada à natureza claramente discreta da variável dependente, sugerem que poderíamos melhorar a formulação linear, estimada via minimos quadrados (MQO), por meio de uma especificação que considera essas características. O modelo de regressão de Poisson tem sido amplamente utilizado para estudar dados com estas características. 


$$
L(\beta)=\sum_{i=1}^{n}\left[-\exp \left(X_{i}^{\prime} \beta\right)+y_{i} X_{i}^{\prime} \beta-\ln y_{i} !\right]
$$

Logo, o EMV para o modelo de Poisson é:

$$
\frac{\partial \ln L}{\partial \beta}=\sum_{i=1}^{n}\left\{\left[y_{i}-\exp \left(X_{i}^{\prime} \beta\right)\right] X_{i}\right\}=0
$$

Para que este estimador seja consistente e eficiente, o Modelo de Poisson impõe que $\operatorname{Var}\left(y_{i} \mid X_{i}^{\prime} \beta\right)=E\left(y_{i} \mid X_{i}^{\prime} \beta\right)$. Contudo, esta hipótese é frequentemente violada. $O$ caso mais comum é a superdispersão (overdispersion) e ocorre quando $\operatorname{Var}\left(y_{i} \mid X_{i}^{\prime} \beta\right)>E\left(y_{i} \mid X_{i}^{\prime} \beta\right)$.

A fim de verificar esta hipótese, Wooldridge (1996) desenvolveu um teste que consiste em regredir $\left(\varepsilon_{t}^{2}-1\right)$ contra $\hat{y}_{t}$ após ter estimado o modelo de Poisson. ${ }^{29}$ Assim, se a estimação resultante obtiver um coeficiente positivo e significativo, haverá um indício de superdispersão e o modelo de Poisson estará mal especificado. ${ }^{30}$

Nesse caso, recomenda-se a utilização de uma generalização do modelo de Poisson conhecida como Modelo Binomial Negativo. Esta especificação introduz um efeito individual não observado $\left(\varepsilon_{i}\right)$ na média condicional $\left(\mu_{i}\right)$. Assim:

$$
\ln \mu_{i}=X_{i}^{\prime} \beta+\varepsilon_{i}=\ln \lambda_{i}+\ln u_{i}
$$

onde o distúrbio $\varepsilon_{i}$ representa o erro de especificação do modelo que deve ser incluído na média condicional. Além disso, $\lambda_{i}=\exp \left(X_{i}^{\prime} \beta\right)$ e $u_{i}=\exp \left(\varepsilon_{i}\right)$. Logo, a distribuição de $y_{i}$ condicionada a $X_{i}$ e $u_{i}$ permanece sendo uma Poisson. Ou seja:

$$
f\left(y_{i} \mid X_{i}^{\prime} \beta, u_{i}\right)=\left[e^{-\lambda_{i} u_{i}}\left(\lambda_{i} u_{i}\right)^{y_{i}}\right] / y_{i} !
$$

Entretanto, a distribuição $f\left(y_{i} \mid X_{i}^{\prime} \beta\right)$ se modifica e transforma-se em:

$$
f\left(y_{i} \mid X_{i}^{\prime} \beta\right)=\int_{0}^{\infty}\left\{\left[e^{-\lambda_{i} u_{i}}\left(\lambda_{i} u_{i}\right)^{y_{i}}\right] / y_{i} !\right\} g\left(u_{i}\right) d u_{i}
$$

29 Onde $\hat{y}_{i}$ é o valor estimado de $y_{i}$ através do modelo de Poisson e $\varepsilon_{i}^{2}=\left(y_{i}-\hat{y}_{i}\right)^{2}$.

30 Outros testes para verificar Superdispersão foram elaborados por Lee (1986), Cameron e Trivedi (1990) e Gurmu (1991). 
Assumindo que $u_{i}$ tem distribuição Gama, do tipo: $\left\{g\left(u_{i}\right)=\left[\theta^{\theta} / \Gamma(\theta)\right]\right.$ $\left.e^{-\theta u_{i}} u_{i}^{\theta-1}\right\}$, é possível mostrar que $f\left(y_{i} \mid X_{i}^{\prime} \beta\right)$ tem média condicional $\left(\lambda_{i}\right) \mathrm{e}$ variância condicional $\left\{\lambda_{i}\left[1+\lambda_{i}(1 / \theta)\right]\right\}$. Então, o modelo Binomial Negativo é capaz de acomodar a super-dispersão, uma vez que sua especificação aceita que $\operatorname{Var}\left(y_{i} \mid X_{i}^{\prime} \beta\right)>E\left(y_{i} \mid X_{i}^{\prime} \beta\right)$.

\subsection{Base de Dados}

As variáveis utilizadas nesta pesquisa foram:

- $N I_{t}$ é o número de investigações $\mathrm{AD}$ abertas entre julho de 1995 e junho de 2010. Os 326 casos abertos neste período foram obtidos nos relatórios semestrais do MIND/SPGC (2011) e foram agrupados em trimestres.

- $\Delta E_{t}$ é a variação da taxa de câmbio real da Argentina. No intuito de obter o câmbio real $(E)$, utilizou-se a taxa de câmbio nominal trimestral da Argentina (relação peso argentino/US\$) disponível no IMF/ISF (2011) multiplicada pelo índice trimestral de preços dos produtos importados pela Argentina (proxy para o nível de preços externos), disponível no INDEC (2011). O valor resultante desta multiplicação foi dividido pelo índice de preços ao consumidor (IPC) trimestral da Argentina (proxy para o nível de preços internos), disponível no IMF/ISF (2011).

- $\Delta T C_{t}$ é a variação do saldo trimestral das transações correntes da argentina, em Milhões de US\$, disponibilizado pelo INDEC (2011).

- $\Delta Y_{t}$ é a variação real do nível de atividade econômica da Argentina. Neste caso, utilizou-se a variação trimestral (dessazonalizada) do PIB argentino da OECD.stat (2011).

- $\Delta Y_{t}^{*}$ é a variação real do índice de atividade econômica externa. Para tanto, foi utilizada a variação trimestral dessazonalizada do PIB das 7 maiores economias do mundo (G7), ${ }^{31}$ disponível no banco de dados da OECD.stat (2011).

- $\Delta Y_{t}^{B R A}$ é a variação real da atividade econômica interna do Brasil. Utilizou-se a Variação do PIB trimestral (dessazonalizado), a preços de mercado, do Brasil. Disponível no sistema de contas nacionais trimestrais do IBGE (2011).

31 Sendo eles: Estados Unidos, Alemanha, Canadá, França, Itália, Japão e Reino Unido. 
No Quadro 1 é possível visualizar as variáveis utilizadas neste trabalho. Cabe relembrar que, antes de efetuar qualquer regressão, deve-se verificar se as variáveis propostas são estacionárias. Caso contrário, as estatísticas t e F perdem credibilidade e podem comprometer a análise dos modelos.

Quadro 1 Apresentação gráfica das variáveis utilizadas

Gráfico 4 Casos antiduming iniciados pela Argentina entre 1995 e 2010

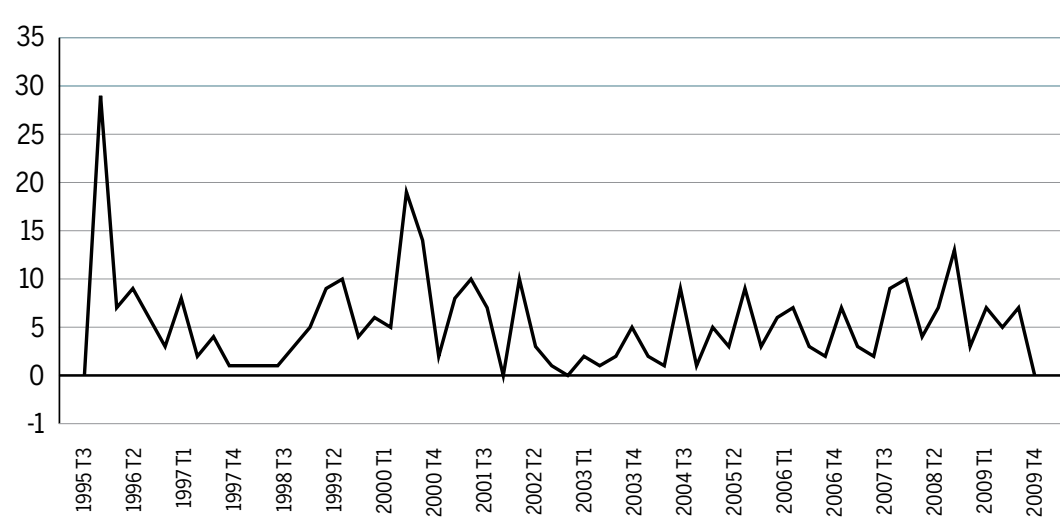

Fonte: Elaborado via MIND/SPGC (2011).

Gráfico 5 Variação do PIB da Argentina, Brasil e G7 entre 1995 e 2010

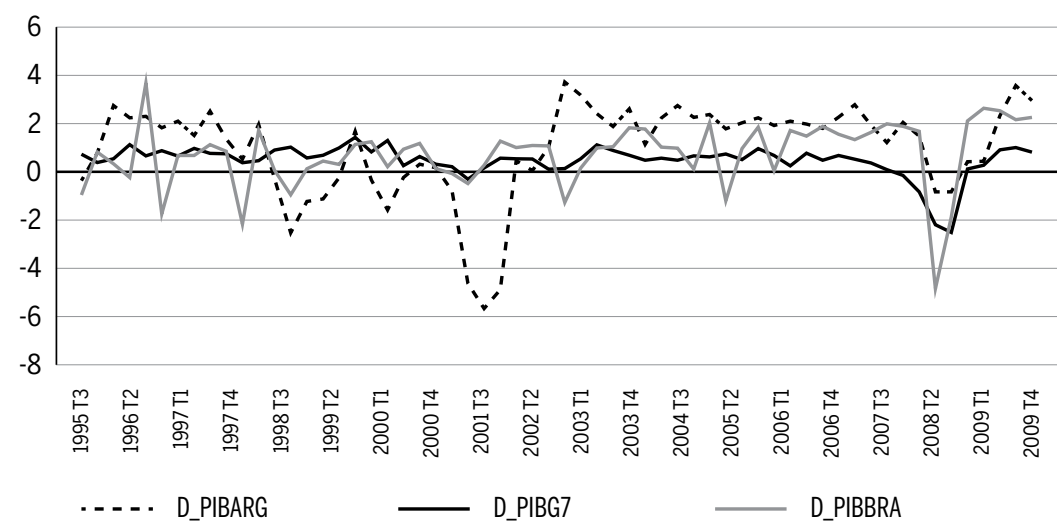

Fonte: Elaborado via OECD.stat (2011) e IBGE (2011). 


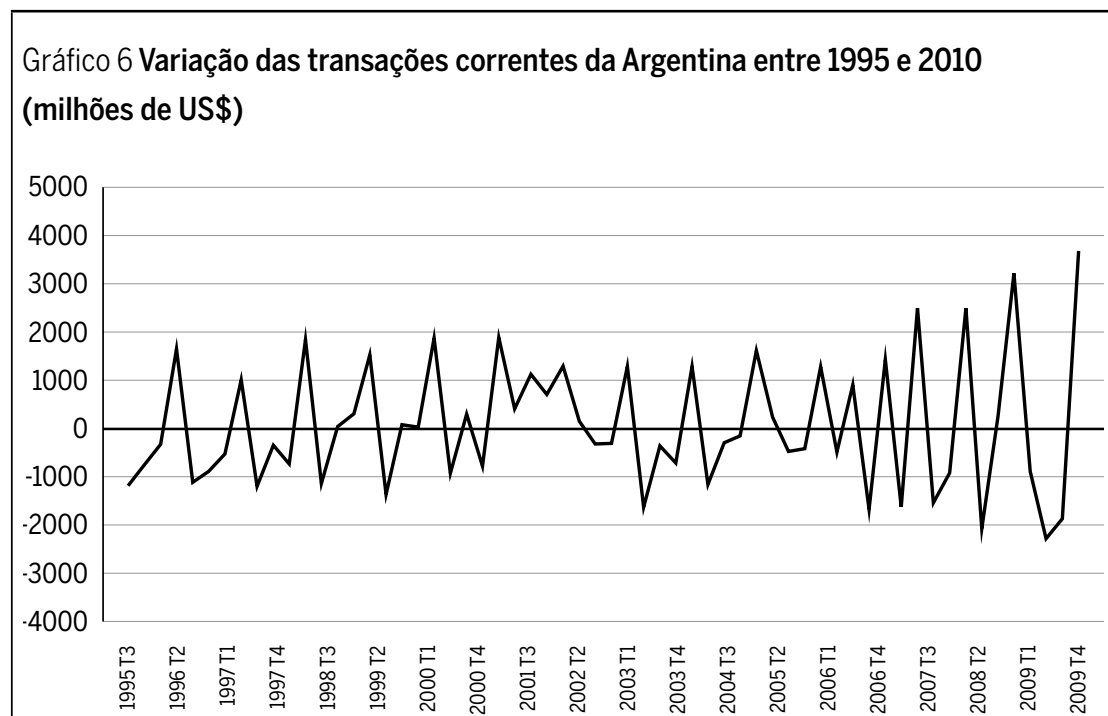

Fonte: Elaborado com base em INDEC (2011).

Gráfico 7 Variação da taxa de câmbio real da Argentina no período de 1995 a 2010

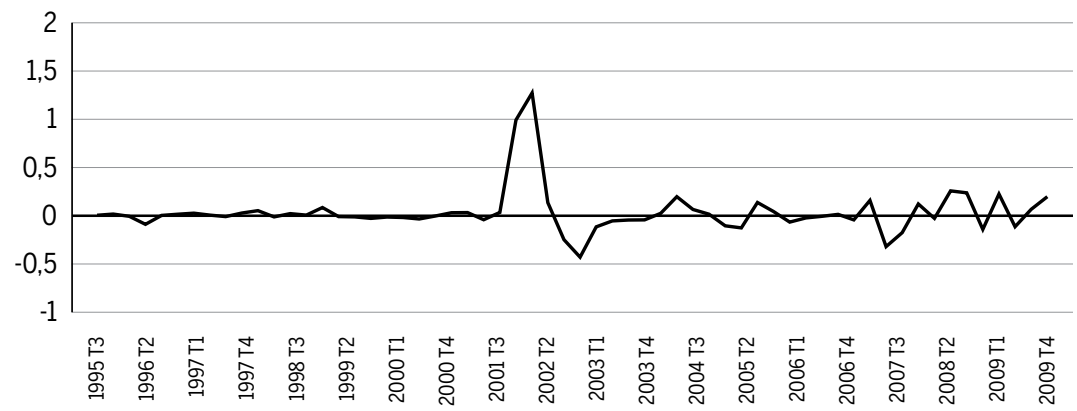

Fonte: Elaborado via INDEC (2011) e IMF/ISF (2011).

Fonte: Elaboração própria com base nos dados já mencionados na seção 5.1.

A Tabela 2 contém o teste de raiz unitária para cada variável utilizada. Uma vez que as variáveis não parecem apresentar tendência, conforme demonstrado no Quadro 1, optou-se pelo procedimento de Dickey Fuller Aumentado apenas com constante. Os resultados indicaram que, considerando um nível de significância de $10 \%$, nenhuma das variáveis apresentou raiz unitária. Então, pode-se dizer que as estatísticas oriundas das estimações realizadas na próxima seção são confiáveis. 
Tabela 2 Teste de estacionariedade das variáveis

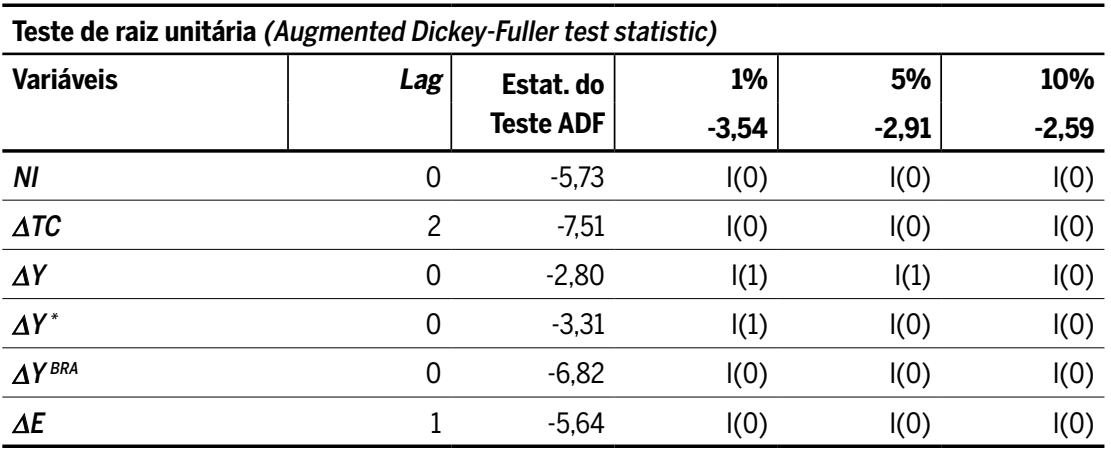

Nota: Os lags poderiam variar de 0 a 10 e foram escolhidos com base no critério de informação de Schwarz.

Fonte: Elaboração própria do autor com base no Eviews 5.

\section{Análise dos resultados}

Inicialmente, buscou-se verificar, com base nas variáveis apresentadas na Equação 1 e no modelo especificado na Equação 2, se a abertura de casos antidumping $(\mathrm{AD})$ na Argentina era afetada por fatores macroeconômicos. Uma vez que a variável dependente apresenta características de uma variável de contagem, optou-se por estimar os modelos não apenas por Mínimos Quadrados Ordinários (MQO), mas também por Poisson e, caso exista superdispersão (overdispersion), Binominal Negativo.

Observando a significância (medida via P-Valor) das variáveis apresentadas na Tabela A.1 (vide Anexo), é possível inferir que diversas variáveis macroeconômicas afetam, estatisticamente, a abertura de casos antidumping na Argentina. Além disso, os valores das estatísticas R2 e R2-Ajustado indicam um bom grau de ajustamento dos modelos. $O$ teste de overdispersion deu negativo e, portanto, o modelo de Poisson seria mais indicado que o Binomial Negativo. Contudo, uma vez que o teste de Jarque-Bera indicou que os resíduos da estimação via $\mathrm{MOO}$ apresentam distribuição normal e o correlograma das defasagens não detectou autocorrelação serial, não haveria motivo para desconsiderar essa regressão.

Uma vez que algumas variáveis explicativas, apresentadas na Tabela A.1, não foram significativas, nem mesmo a 10\% de significância, buscou-se melhorar as estimações por meio da exclusão das variáveis menos 
relevantes. Assim, variáveis foram excluídas, com base em suas respectivas estatísticas $t$, até que uma nova exclusão causasse uma piora no Critério de Schwarz (SC). Os resultados deste processo estão disponíveis na Tabela 3.

É importante notar que, independente do modelo considerado, a exclusão das variáveis menos relevantes parece ter sido benéfica, tanto pelo critério SC quanto pelo R2-Ajustado. Portanto, a redução no número de variáveis parece ter melhorado o poder de explicação dos modelos. Mais uma vez, não verificou-se overdispesion e não haveria necessidade de considerar o modelo Binomial Negativo (Tabela 3).

O teste de Jarque-Bera manteve a normalidade dos resíduos associados ao MQO e acusou não normalidade nas demais especificações (Poisson e Binominal Negativo) (Tabela 3). Todavia, isso não é necessariamente um problema, visto que tais modelos não pressupõem a existência de normalidade (ver seção 5).

Tabela 3 Impactos de fatores macroeconômicos sobre a abertura de casos antidumping na Argentina, entre 1995 e 2010: modelos ajustados

\begin{tabular}{|c|c|c|c|c|c|c|}
\hline \multirow[t]{2}{*}{ Variável } & \multicolumn{2}{|r|}{ MQO } & \multicolumn{2}{|r|}{ Poisson } & \multicolumn{2}{|c|}{ Binomial Negativo } \\
\hline & Coeficiente & P-Valor & Coeficiente & P-Valor & Coeficiente & P-Valor \\
\hline Cte & 14,719 & 0,00 & 2,923 & 0,00 & 3,172 & 0,00 \\
\hline$\Delta T C$ & $-0,002$ & 0,00 & $-0,000$ & 0,00 & $-0,000$ & 0,00 \\
\hline$\Delta Y$ & 1,154 & 0,00 & 0,333 & 0,00 & 0,254 & 0,00 \\
\hline$\Delta Y^{*}$ & $-6,135$ & 0,00 & $-0,958$ & 0,00 & $-1,000$ & 0,00 \\
\hline$\Delta Y^{B R A}$ & 0,827 & 0,00 & 0,287 & 0,00 & 0,290 & 0,00 \\
\hline$\Delta E$ & $-6,174$ & 0,00 & $-1,948$ & 0,00 & $-2,112$ & 0,00 \\
\hline$\Delta T C \quad(-1)$ & 0,002 & 0,01 & 0,001 & 0,00 & 0,001 & 0,00 \\
\hline$\Delta Y \quad(-1)$ & $-2,163$ & 0,00 & $-0,745$ & 0,00 & $-0,654$ & 0,00 \\
\hline$\Delta Y^{*} \quad(-1)$ & 3,432 & 0,00 & n.s & n.s & n.s & n.s \\
\hline$\Delta Y^{B R A}(-1)$ & $-1,228$ & 0,00 & $-0,173$ & 0,00 & $-0,199$ & 0,00 \\
\hline$\Delta E \quad(-1)$ & $-2,299$ & 0,12 & $-0,708$ & 0,01 & n.s & n.s \\
\hline$\triangle T C \quad(-2)$ & 0,004 & 0,00 & 0,001 & 0,00 & 0,001 & 0,00 \\
\hline$\Delta Y \quad(-2)$ & 1,987 & 0,00 & 0,667 & 0,00 & 0,681 & 0,00 \\
\hline$\Delta Y^{*} \quad(-2)$ & 1,491 & 0,02 & 0,538 & 0,00 & 0,583 & 0,00 \\
\hline$\Delta Y^{B R A}(-2)$ & $-2,691$ & 0,00 & $-0,401$ & 0,00 & $-0,390$ & 0,00 \\
\hline$\Delta E \quad(-2)$ & 2,582 & 0,14 & 0,772 & 0,00 & n.s & n.s \\
\hline
\end{tabular}


Tabela 3 (continuação)

\begin{tabular}{|c|c|c|c|c|c|c|c|}
\hline \multirow{2}{*}{\multicolumn{2}{|c|}{ Variável }} & \multicolumn{2}{|r|}{ MQO } & \multicolumn{2}{|r|}{ Poisson } & \multicolumn{2}{|c|}{ Binomial Negativo } \\
\hline & & Coeficiente & P-Valor & Coeficiente & P-Valor & Coeficiente & P-Valor \\
\hline$\Delta T C$ & $(-3)$ & 0,002 & 0,00 & 0,000 & 0,00 & 0,000 & 0,00 \\
\hline$\Delta Y$ & $(-3)$ & n.s & n.s & $-0,182$ & 0,00 & $-0,157$ & 0,04 \\
\hline$\Delta Y^{*}$ & $(-3)$ & 1,682 & 0,04 & 0,282 & 0,00 & 0,349 & 0,02 \\
\hline$\Delta Y^{B R A}$ & $(-3)$ & n.s & n.s & 0,052 & 0,18 & n.s & n.s \\
\hline$\Delta E$ & $(-3)$ & $-34,442$ & 0,00 & $-8,987$ & 0,00 & $-8,342$ & 0,00 \\
\hline$\Delta T C$ & $(-4)$ & 0,004 & 0,00 & 0,001 & 0,00 & 0,001 & 0,00 \\
\hline$\Delta Y$ & $(-4)$ & n.s & n.s & n.s & n.s & n.s & n.s \\
\hline$\Delta Y^{*}$ & $(-4)$ & 1,943 & 0,06 & $-0,182$ & 0,06 & $-0,190$ & 0,16 \\
\hline$\Delta Y^{B R A}$ & $(-4)$ & n.s & n.s & n.s & n.s & n.s & n.s \\
\hline$\Delta E$ & $(-4)$ & 10,902 & 0,00 & 4,117 & 0,00 & 3,730 & 0,00 \\
\hline$\Delta T C$ & $(-5)$ & 0,001 & 0,02 & n.s & n.s & n.s & n.s \\
\hline$\Delta Y$ & $(-5)$ & $-0,585$ & 0,07 & $-0,208$ & 0,00 & $-0,236$ & 0,00 \\
\hline$\Delta Y^{*}$ & $(-5)$ & $-7,046$ & 0,00 & $-0,597$ & 0,00 & $-0,839$ & 0,00 \\
\hline$\Delta Y^{B R A}$ & $(-5)$ & 1,260 & 0,00 & 0,258 & 0,00 & 0,275 & 0,00 \\
\hline$\Delta E$ & $(-5)$ & $-18,387$ & 0,00 & $-3,925$ & 0,00 & $-3,778$ & 0,00 \\
\hline$\Delta T C$ & $(-6)$ & $-0,002$ & 0,00 & $-0,001$ & 0,00 & $-0,001$ & 0,00 \\
\hline$\Delta Y$ & $(-6)$ & $-2,121$ & 0,00 & $-0,284$ & 0,00 & $-0,207$ & 0,00 \\
\hline$\Delta Y^{*}$ & $(-6)$ & $-5,953$ & 0,00 & $-0,807$ & 0,00 & $-0,994$ & 0,00 \\
\hline$\Delta Y^{B R A}$ & $(-6)$ & 0,963 & 0,03 & 0,173 & 0,00 & 0,115 & 0,00 \\
\hline$\Delta E$ & $(-6)$ & $-4,669$ & 0,04 & n.s & n.s & n.s & n.s \\
\hline$\Delta T C$ & $(-7)$ & $-0,001$ & 0,00 & $-0,000$ & 0,00 & $-0,000$ & 0,00 \\
\hline$\Delta Y$ & $(-7)$ & 3,087 & 0,00 & 0,724 & 0,00 & 0,681 & 0,00 \\
\hline$\Delta Y^{*}$ & $(-7)$ & 3,455 & 0,00 & 0,532 & 0,00 & 0,439 & 0,03 \\
\hline$\Delta Y^{B R A}$ & $(-7)$ & $-3,011$ & 0,00 & $-0,597$ & 0,00 & $-0,691$ & 0,00 \\
\hline$\Delta E$ & $(-7)$ & $-5,423$ & 0,01 & $-0,546$ & 0,00 & $-0,711$ & 0,00 \\
\hline$\Delta T C$ & $(-8)$ & n.s & n.s & 0,000 & 0,00 & $-0,000$ & 0,00 \\
\hline$\Delta Y$ & $(-8)$ & $-1,891$ & 0,00 & $-0,381$ & 0,00 & $-0,374$ & 0,00 \\
\hline$\Delta Y^{*}$ & $(-8)$ & n.s & n.s & $-0,451$ & 0,00 & $-0,244$ & 0,24 \\
\hline$\Delta Y^{B R A}$ & $(-8)$ & $-2,014$ & 0,00 & $-0,415$ & 0,00 & $-0,453$ & 0,00 \\
\hline$\Delta E$ & $(-8)$ & $-6,517$ & 0,01 & n.s & n.s & n.s & n.s \\
\hline $\mathrm{R}^{2}$ & & & 0,987 & & 0,992 & & 0,949 \\
\hline$R^{2}-A j u$ & ustado & & 0,943 & & 0,968 & & 0,827 \\
\hline SC & & & 4,325 & & 6,187 & & 7,628 \\
\hline
\end{tabular}


Tabela 3 (continuação)

\begin{tabular}{l|r|r|r|r|r|r}
\hline Variável & MQO & & Poisson & \multicolumn{2}{r}{ Binomial Negativo } \\
\cline { 2 - 6 } & Coeficiente & P-Valor & Coeficiente & P-Valor & Coeficiente & P-Valor \\
\hline Jarque-Bera & 2,426 & 6,854 & 39,979 \\
(p-valor) & $(0,297)$ & $(0,03)$ & $(0,00)$ \\
\hline Overdispersion & n.a & Não & n.a \\
\hline
\end{tabular}

Nota: 1) n.s - não significativo; n.a - não se aplica. 2) 0 correlograma, que mede a existência de autocorrelação nos resíduos, não identificou este problema em nenhuma das regressões (considerou-se 16 defasagens).

Fonte: Elaboração própria com base no Eviews 5.

A fim de melhor entender os resultados da Tabela 3, os coeficientes associados a cada variável foram subdivididos em impactos de "curto prazo" e "longo prazo". Assim, chamou-se de curto prazo o impacto contemporâneo associado a uma variável (sem defasagem). Já o "longo prazo" foi definido como o somatório das defasagens consideradas (8 trimestres) (Tabela 4).

Tabela 4 Impactos de curto e longo prazo sobre a abertura de casos antidumping na Argentina (baseado nos coeficientes da Tabela 3)

\begin{tabular}{|c|c|c|c|c|c|c|c|c|c|}
\hline & \multicolumn{3}{|r|}{$\begin{array}{r}\text { Impactos } \\
(M Q O)\end{array}$} & \multicolumn{3}{|c|}{$\begin{array}{l}\text { Impactos } \\
\text { (Poisson) }\end{array}$} & \multicolumn{3}{|c|}{$\begin{array}{r}\text { Impactos } \\
\text { (Binomial Negativo }\end{array}$} \\
\hline & $\begin{array}{l}\text { Curto } \\
\text { Prazo }\end{array}$ & $\begin{array}{l}\text { Longo } \\
\text { Prazo }\end{array}$ & Total & $\begin{array}{l}\text { Curto } \\
\text { Prazo }\end{array}$ & $\begin{array}{l}\text { Longo } \\
\text { Prazo }\end{array}$ & Total & $\begin{array}{l}\text { Curto } \\
\text { Prazo }\end{array}$ & $\begin{array}{r}\text { Longo } \\
\text { Prazo }\end{array}$ & Total \\
\hline lag & 0 & 1 a 8 & 0 a 8 & 0 & 1 a 8 & 0 a 8 & 0 & 1 a 8 & 0 a 8 \\
\hline$\Delta T C$ & $-0,0019$ & 0,0104 & 0,0086 & $-0,0003$ & 0,0020 & 0,0017 & $-0,0003$ & 0,0023 & 0,0020 \\
\hline$\Delta Y$ & 1,1539 & $-1,6861$ & $-0,5322$ & 0,3330 & $-0,4072$ & $-0,0742$ & 0,2537 & $-0,2650$ & $-0,0113$ \\
\hline$\Delta Y^{*}$ & $-6,1352$ & $-0,9954$ & $-7,1306$ & $-0,9584$ & $-0,6841$ & $-1,6425$ & $-1,0004$ & $-0,8951$ & $-1,8955$ \\
\hline$\Delta Y^{B R A}$ & 0,8268 & $-6,7214$ & $-5,8946$ & 0,2867 & $-1,1019$ & $-0,8152$ & 0,2905 & $-1,3428$ & $-1,0523$ \\
\hline \multirow[t]{2}{*}{$\Delta E$} & $-6,1741$ & $-58,2539$ & $-64,4280$ & $-1,9478$ & $-9,2761$ & $-11,2239$ & $-2,1122$ & $-9,1008$ & $-11,2129$ \\
\hline & \multicolumn{3}{|c|}{$\begin{array}{r}\text { Distribuição dos Impactos } \\
\text { (MQO) }\end{array}$} & \multicolumn{3}{|c|}{$\begin{array}{r}\text { Distribuição dos Impactos } \\
\text { (Poisson) }\end{array}$} & \multicolumn{3}{|c|}{$\begin{array}{r}\text { Distribuição dos Impactos } \\
\text { (Binomial Negativo) }\end{array}$} \\
\hline$\Delta T C$ & $-21,64$ & 121,64 & 100,00 & $-20,55$ & 120,55 & 100,00 & $-14,99$ & 114,99 & 100 \\
\hline$\Delta Y$ & $-216,81$ & 316,81 & 100,00 & $-448,90$ & 548,90 & 100,00 & $-2239,36$ & 2339,36 & 100 \\
\hline$\Delta Y^{*}$ & 86,04 & 13,96 & 100,00 & 58,35 & 41,65 & 100,00 & 52,78 & 47,22 & 100 \\
\hline$\Delta Y^{B R A}$ & $-14,03$ & 114,03 & 100,00 & $-35,17$ & 135,17 & 100,00 & $-27,60$ & 127,60 & 100 \\
\hline$\Delta E$ & 9,58 & 90,42 & 100,00 & 17,35 & 82,65 & 100,00 & 18,84 & 81,16 & 100 \\
\hline
\end{tabular}

Fonte: Elaboração própria com base nos resultados da Tabela 3. 
De modo geral, os resultados da Tabela 4 revelam que todos os modelos convergiram em termos de sinal. Em outras palavras, a direção do impacto de curto e longo prazo, associado a uma variável qualquer, não muda entre os modelos. Apenas a magnitude do efeito é alterada. No que se refere ao efeito de curto e longo prazo, é possível notar que apenas a renda externa $\left(\Delta Y^{*}\right)$ causaria um impacto de curto prazo superior ao de longo. Portanto, as variáveis defasadas seriam mais importantes para definir a abertura de processos $\mathrm{AD}$ quando comparadas às variáveis contemporâneas.

Quanto ao efeito total de cada variável, verificou-se que uma desvalorização cambial $(\Delta E)$ ou um crescimento nas rendas da Argentina $(\Delta Y)$, do Brasil $\left(\Delta Y^{B R A}\right)$ e do resto do mundo $\left(\Delta Y^{*}\right)$ tenderiam a reduzir o número de processos $\mathrm{AD}$ abertos pela Argentina. Enquanto isso, uma melhora nas transações correntes $(\triangle T C)$ tenderia a aumentar o número de casos (Tabela 4). Embora este último resultado não esteja de acordo com a teoria apresentada na seção 4, de que uma melhora em $T C$ reduziria o número de processos $\mathrm{AD}$, verificou-se que isto procede no curto prazo. Assim, uma melhora em $T C$ tenderia a reduzir os casos $\mathrm{AD}$ num primeiro momento. Contudo, é possível que uma melhora atual nas transações correntes favoreça a importação de novos produtos no futuro (devido à maior disponibilidade de moeda estrangeira), o que impulsionaria o número de casos antidumping. ${ }^{32}$

No intuito de testar a capacidade preditiva dos modelos apresentados na Tabela 3, buscou-se verificar qual seria o número de investigações $\mathrm{AD}$ iniciadas pela Argentina entre o $1^{\circ}$ trimestre de 2008 e $2^{\circ}$ trimestre de 2010 (totalizando 10 períodos), caso apenas as variáveis explicativas fossem conhecidas neste período. A estratégia utilizada consistiu em regredir os modelos da Tabela 3, considerando apenas o período entre julho de 1995 ( $3^{\circ}$ trimestre) a dezembro de 2007 ( $4^{\circ}$ trimestre). Feito isto, utilizou-se os coeficientes dessas regressões e os valores das demais variáveis explicativas, entre janeiro de 2008 ( $1^{\circ}$ trimestre) e junho de 2010 ( ${ }^{\circ}$ trimestre), a fim de obter o número de casos $\mathrm{AD}$ que seriam iniciados na Argentina no período (Tabela 5).

32 Como os autores mencionados nesta pesquisa concentraram suas análises apenas no impacto total gerado pelas variáveis macroeconômicas, não é possível comparar os impactos de "curto-prazo" e "longo-prazo" apresentados na Tabela 4. Além disso, algumas questões ainda precisam ser aprofundadas, como o fato do crescimento nas rendas da Argentina $(\Delta Y)$ e do Brasil $\left(\triangle Y^{B R A}\right)$ apresentarem impactos distintos no curto e no longo prazo. 
Tabela 5 Previsão de abertura de investigações antidumping na Argentina entre 2008 e 2010

\begin{tabular}{|c|c|c|c|c|c|c|c|}
\hline \multirow[t]{3}{*}{ Período } & \multirow{3}{*}{$\begin{array}{l}\text { Número } \\
\text { de inves- } \\
\text { tigações } \\
\text { AD (valo- } \\
\text { res reais) }\end{array}$} & & & \multicolumn{4}{|c|}{ Número de Investigações AD Estimadas } \\
\hline & & \multicolumn{3}{|c|}{ Valores inteiros (arredondados) } & \multicolumn{3}{|c|}{ Valores com 2 casas decimais } \\
\hline & & MQO & Poisson & $\begin{array}{l}\text { Bin. } \\
\text { Neg. }\end{array}$ & MQO & Poisson & $\begin{array}{l}\text { Bin. } \\
\text { Neg. }\end{array}$ \\
\hline $2008 \mathrm{~T} 1$ & 9 & 8 & 18 & 18 & 7.69 & 17.81 & 17.91 \\
\hline $2008 \mathrm{~T} 2$ & 10 & 7 & 8 & 15 & 7.02 & 8.43 & 14.66 \\
\hline 2008 T3 & 4 & 7 & 2 & 3 & 6.77 & 1.57 & 3.27 \\
\hline 2008 T4 & 7 & 12 & 15 & 11 & 11.54 & 15.20 & 11.38 \\
\hline $2009 \mathrm{~T} 1$ & 13 & 13 & 2 & 3 & 12.80 & 1.79 & 3.04 \\
\hline 2009 T2 & 3 & 1 & 7 & 5 & 1.13 & 6.92 & 4.97 \\
\hline 2009 T3 & 7 & -4 & 5 & 3 & -3.80 & 5.12 & 2.77 \\
\hline 2009 T4 & 5 & 7 & 8 & 34 & 7.28 & 8.30 & 33.92 \\
\hline 2010 T1 & 7 & 7 & 3 & 2 & 6.64 & 3.49 & 1.88 \\
\hline 2010 T2 & 0 & 0 & 0 & 0 & 0.13 & 0.04 & 0.03 \\
\hline Média & 6,50 & & & & 5,72 & 6,87 & 9.38 \\
\hline Soma dos & uadrados do & resíduos & & & 164,41 & 320,94 & 1104,39 \\
\hline
\end{tabular}

Fonte: Elaboração própria com base no Eviews 5.

Analisando os valores previstos apresentados na Tabela 5, conclui-se que os modelos de Poisson e Binomial Negativo apresentam a vantagem de evitar a incidência de valores negativos. Fato que não ocorre com o $\mathrm{MQO}$ (ver 2009 T3 na Tabela 5). Além disso, o modelo de Poisson foi o que mais se aproximou do valor médio do período. Segundo essa especificação, a Argentina abriria aproximadamente, 6,9 investigações AD a cada trimestre. Valor próximo aos 6,5 casos realmente iniciados a cada trimestre no período. Contudo, foi o modelo de $\mathrm{MQO}$ que produziu os menores resíduos e, portanto, produziria predições com maior acurácia quando comparado aos demais.

\section{Conclusão}

Este trabalho verificou o impacto de fatores macroeconômicos sobre a abertura de casos antidumping (AD) na Argentina e se, com base em tais 
impactos, seria possível prever adequadamente o uso do $\mathrm{AD}$ neste país. Para tanto, utilizou-se dados trimestrais (referentes ao período de 1995 a 2010) e, conforme sugerido por Knetter e Prusa (2003) e Aggarwal (2004), foi considerada uma defasagem de 2 anos (8 trimestres) para as variáveis explicativas.

Uma vez que o número de investigações $\mathrm{AD}$ apresenta características de uma variável de contagem, optou-se por estimar os modelos não apenas por Mínimos Quadrados Ordinários (MQO), mas também por Poisson e, caso exista superdispersão (overdispersion), Binominal Negativo.

A revisão dos trabalhos dessa área revelou que o número de casos $\mathrm{AD}$ iniciados por um país pode ser afetado por oscilações na renda interna e externa e por variações na taxa de câmbio real e no saldo em transações correntes. Além disso, devido ao elevado número de instigações $\mathrm{AD}$ contra o Brasil, optou-se por subdividir a renda externa em: renda do Brasil e renda do resto do mundo. Sendo assim, será possível identificar que impacto uma variação na renda brasileira causaria na abertura de casos $\mathrm{AD}$ na Argentina.

As estimações realizadas apresentaram elevado poder de explicação e indicaram que diversas variáveis macroeconômicas afetariam a abertura de casos $\mathrm{AD}$ na Argentina. A exclusão das variáveis menos relevantes se mostrou benéfica aos modelos e permitiu verificar que as variáveis defasadas causam maiores impactos sobre a abertura de processos $\mathrm{AD}$ quando comparadas às variáveis contemporâneas.

Quanto ao efeito total de cada variável, verificou-se que uma desvalorização cambial ou um crescimento nas rendas da Argentina, do Brasil, e do resto do mundo tenderiam a reduzir o número de casos $\mathrm{AD}$ abertos pela Argentina. Enquanto isso, uma melhora nas transações correntes tenderia a aumentá-los. Embora este último resultado não esteja de acordo com a teoria, verificou-se que isto procede no curto prazo. Assim, uma melhora nas transações correntes tenderia a reduzir os casos $\mathrm{AD}$ num primeiro momento. Contudo, é possível que uma melhora atual nas transações correntes favoreça a importação de novos produtos no futuro (devido à maior disponibilidade de moeda estrangeira), o que aumentaria o número de casos.

Ao utilizar modelos no intuito de averiguar suas respectivas capacidades preditivas, concluiu-se que os modelos de Poisson e Binomial Negativo apresentam a vantagem de evitar a incidência de valores negativos. Fato que não ocorre com o MQO. Além disso, o modelo de Poisson foi o que mais se aproximou do número real médio de medidas $\mathrm{AD}$ iniciadas a cada 
trimestre pela Argentina. Contudo, foi o modelo de MQO que produziu os menores resíduos e, portanto, produziria predições com maior acurácia quando comparado aos demais.

De modo geral, os resultados indicaram que a autoridade reguladora argentina é influenciada por oscilações macroeconômicas. Uma vez que o objetivo do instrumento antidumping consiste em evitar o comércio desleal e a OMC estabelece regras específicas para o seu uso, tal influência não deveria ocorrer e indicaria um mau uso deste recurso. Cabe ressaltar, ainda, que previsões que indiquem um crescimento do número de investigações $\mathrm{AD}$ na Argentina poderiam ser utilizadas na defesa de empresas estrangeiras (inclusive brasileiras) que estiverem sendo alvo dessas medidas no período considerado nas previsões. Por fim, como Firme e Vasconcelos (2013) revelam que apenas 3 setores (metais comuns, indústria química e plástico/borracha) seriam alvos de mais de $60 \%$ dos casos $\mathrm{AD}$ no mundo, tais previsões poderiam ser do interesse de empresas pertencentes a esses setores.

\section{Referências}

AGGARWAL, A. Macroeconomic determinants of antidumping: a comparative analysis of developed and developing countries. World Development. v. 32, n. 6, p. 1043-1057, 2004.

AHN, D.; SHIN, W. Analysis of Anti-dumping Use in Free Trade Agreements. Journal of World Trade, v. 45, Issue 2, p. 431-456, 2011.

AMITI, M.; FREUND, C. The Anatomy of China's Export Growth. The World Bank - Development Research Group. Trade Team: Policy Reseach Working Paper, n. 4628, 2008.

BATISTA JR., P. N. Argentina: uma crise paradigmática. Estudos Avançados, v. 16, n. 44, 2002.

BECKER, B.; THEURINGER, M. Macroeconomic determinants of contingent protection: The case of the EU. Zeitschrift für Wirtschaftspolitik (Journal for Economic Policy), 50(3), 2001.

BELLO, T. S. Algumas considerações sobre a crise argentina. Indic. Econ. FEE. Porto Alegre, v. 30, n. 2, p. 251-296. set. 2002.

BLONIGEN, B.; PRUSA, T. Antidumping. National Bureau of Economic Research - NBER Working Paper, n. 8398, 2001.

BOWN, C. P. Taking Stock of Antidumping, Safeguards and Countervailing Duties, 1990 2009. The World Economy, 34(12), p. 1955-1988, 2011.

CAMERON, A. C.; TRIVEDI, P. K. Regression-based Tests for Overdispersion in the Poisson Model. Journal of Econometrics, n. 46, 347-364, 1990.

EVENETT, S. J. The simple analytics of U.S. antidumping orders: Bureaucratic discretion, anti-importer bias, and the Byrd amendment. European Journal of Political Economy, v. 22 p.732-749, 2006. 
FEINBERG, R. M. Exchange rate and unfair trade. Review of Economics and Statistics, v. 71, n. 4, p. 704-707, 1989.

FEINBERG R. U.S. Antidumping Enforcement and Macroeconomic Indicators Revisited: Do Petitioners Learn? Review of World Economics, v. 141, n. 4, p. 612-622. December 2005.

FEINBERG, R. M. Antidumping and the global financial crisis: the impact on Latin America and the Caribbean. ECLAC - Studies and Perspectives series, Washington, n. 9, 2010.

FINGER, J. M.; HALL, K.; NELSON, D. The political economy of administered protection. American Economic Review. v. 72, n. 3, p. 452-466, 1982.

FIRME, V. A. C.; VASCONCELOS, C. R. F. Impactos de medidas antidumping adotadas pelos EUA sobre o setor siderúrgico de Minas Gerais e o restante do Brasil. Revista Nova Economia. Belo Horizonte, 22 (2), 261-302, 2012.

FIRME, V. A. C.; VASCONCELOS, C. R. F. Evolução no uso do mecanismo antidumping após a Rodada Uruguai. $41^{\circ}$ Encontro Nacional de Economia - ANPEC, Foz do Iguaçu - PR. 2013.

FIRME, V. A. C.; VASCONCELOS, C. R. F. Evolution in the use of antidumping mechanism after Uruguay round. Revista Economia - ANPEC, v. 16, p. 321-342. 2015.

FRANCOIS, J. F.; NEILS, G. Political influence in a new antidumping regime. Rotterdam: Tinbergen Institute, Discussion Paper, TI, 2004-011/2, 2004.

GREENE, W. H. Econometrics Analysis. Upper Saddle River, NJ: Prentice Hall, 1997.

GREENE, W. H. Econometric Analysis. Upper Saddle River, NJ: Prentice Hall, 2002.

GURMU, S. Tests for Detecting Overdispersion in the Positive Poisson Regression Model. Journal of Business and Economic Statistics, 9, p. 215-222, 1991.

HANSEN, W. L.; PRUSA, T. J. The economics and politics of trade policy: an empirical analysis of ITC decision making. Review of International Economics. v. 5, n. 2, p. 230-245, 1997.

IRWIN, D. A. The Rise of U.S. Antidumping Activity in Historical Perspective. The World Economy, 28 (5), p. 651-668, 2005.

KNETTER, M. M.; PRUSA, T. J. Macroeconomic factors and antidumping filings: evidence from four countries. Journal of International Economics, v. 61, p. 1-17, 2003.

KONING, J.; VANDENBUSSCHE, H.; SPRINGAEL, L. Import Diversion under European Antidumping Policy. National Bureau of Economic Research - NBER Working Paper, n. 7340, 1999.

LEE, L. Specification Tests for Poisson Regression Models. International Economic Review, 27, p. 689-706, 1986.

LEIDY, M. P. Macroeconomic Conditions and Pressures for Protection under Antidumping and Countervailing Duty Laws: Empirical Evidence from the United States. IMF Staff Papers, 44, p.132-44, 1997.

MOORE, M. O.; ZANARDI, M. Trade Liberalization and Antidumping: Is There a Substitution Effect? Review of Development Economics, v. 15(4), p. 601-619, nov. 2011.

MIRANDA, P. Aplicação do direito Antidumping e o impacto sobre as exportações brasileiras. Documento IPEA/CEPAL, 2003.

NELSON, D. The Political Economy of Antidumping: A Survey. European Journal of Political Economy, 22(3), p. 554-590, 2004. 
NIELS, G.; FRANCOIS, J. Business cycles, the exchange rate, and demand for antidumping in México. Review of Development Economics, v. 10, n. 3, p. 388-399, 2006.

OSSA, R. A "New Trade" Theory of GATT/WTO Negotiations. Journal of Political Economy, vol. 119, n. 1, 2011.

PRUSA, T. The Trade Effects of U.S. Antidumping Actions. National Bureau of Economic Research - NBER Working Paper, n. 5440. Cambridge, 1996.

PRUSA, T. J. On the spread and impact of antidumping. National Bureau of Economic Research - NBER Working Paper, n. 7404. Cambridge, 1999.

QUINN, J.; SLAYTON, P. Non-tariff Barriers After the Tokyo Round. Proceedings of a Conference Sponsored by the Canada-united States Law Institute, London, Ontario 8-10 May 1980. Montreal: Institute for Research on Public Policy, 1982.

STAIGER, R.; WOLAK, F. Measuring industry-specific protection: antidumping in the United States. Brookings papers on Economic Activity, Microeconomics, p.51-118, 1994.

SUDSAWASD, S. Tariff Liberalization and the Rise of Anti-dumping Use: Empirical Evidence from Across World Regions. The International Trade Journal, v. 26(1), p. 4-18, 2012.

TAKACS,W. E., Pressures for Protectionism: an Empirical Analysis. Economic Inquiry. v. 19, p. 687-93, 1981.

TREBILCOCK, M.; HOWSE, R. The Regulation of International Trade. London: Routledge, 2002.

VANDENBUSSCHE, H.; ZANARDI, M. The Chilling Trade Effects of Antidumping Proliferation. European Economic Review, v. 54(6), p.760-777, 2010.

VASCONCELOS, C. R. F. ; FIRME, V. A. C. Efetividade do Instrumento Antidumping no Brasil entre 1990 e 2007. Revista EconomiA (Brasília), v. 12, p. 165-184, 2011.

WILLIG, R. D. Economic Effects of Antidumping Policy. In: Lawrence, R. Z. (Ed.) Brookings Trade Fórum 1998. Washington: Brookings Institution Press, 1998.

WOOLDRIDGE, J. M. Quasi-likelihood methods for count data. In: Pesaran, H.; Schimidt, P. (eds). Handbook of Applied Econometrics, Blackwell, Malden, MA. p. 352-406, 1996.

WOOLDRIDGE, J. M. Econometric Analysis of Cross Section and Panel Data. London (England): The MIT Press, 2002.

ZANARDI, M. Anti-dumping: What are the Numbers to Discuss at Doha? The Word Economy, v. 27, n. 3, p. 403-433, 2004.

\section{Sites}

ALICEweb. Sistema de Análise das Informações de Comércio Exterior: http://aliceweb. desenvolvimento.gov.br. Acesso em 2015.

IBGE. Instituto Brasileiro de Geografia e Estatística. Disponível: http://www.ibge.gov.br. Acesso em 2011.

IMF/ISF. International Monetary Fund / International Financial Statistics: http://www.imf. org/external/data.htm. Acesso em 2011.

INDEC. Instituto Nacional de Estadística y Censos de Argentina: http://www.indec.mecon. ar/. Acesso em 2011. 
MIND/SPGC. Ministerio de Industria - Subsecretaría de Política y Gestión Comercial: http:// www.comercio.gov.ar. Acesso em 2011.

OECD stat. Organisation for Economic Co-operation and Development: http://stats.oecd. org. Acesso em 2011.

WTO - World Trade Organization: Trade Topics/Anti-Dumping: www.wto.org. Acesso em 2015.

\section{Sobre o autor}

Vinicius de Azevedo Couto Firme - vinicius.firme@ufjf.edu.br

Universidade Federal de Juiz de Fora, Campus Governador Valadares - UFJF/GV, Governador Valadares, Minas Gerais.

\section{Sobre o artigo}

Recebido em 31 de outubro de 2015. Aprovado em 15 de setembro de 2016. 


\section{APÊNDICE}

Tabela A1 Impactos de fatores macroeconômicos sobre a abertura de casos antidumping na Argentina, entre 1995 e $2010^{33}$

\begin{tabular}{|c|c|c|c|c|c|c|}
\hline \multirow[t]{2}{*}{ Variável } & \multicolumn{2}{|r|}{ MQO } & \multicolumn{2}{|r|}{ Poisson } & \multicolumn{2}{|c|}{ Binomial Negativo } \\
\hline & Coeficiente & P-Valor & Coeficiente & P-Valor & Coeficiente & P-Valor \\
\hline Cte & 15,536 & 0,00 & 3,012 & 0,00 & 3,050 & 0,00 \\
\hline$\Delta T C$ & $-0,002$ & 0,03 & 0,000 & 0,00 & 0,000 & 0,00 \\
\hline$\Delta Y$ & 1,140 & 0,01 & 0,315 & 0,00 & 0,225 & 0,01 \\
\hline$\Delta Y^{*}$ & $-6,214$ & 0,00 & $-0,826$ & 0,00 & $-0,870$ & 0,00 \\
\hline$\Delta Y^{B R A}$ & 1,150 & 0,02 & 0,293 & 0,00 & 0,285 & 0,00 \\
\hline$\Delta E$ & $-6,485$ & 0,01 & $-2,232$ & 0,00 & $-1,953$ & 0,00 \\
\hline$\Delta T C \quad(-1)$ & 0,003 & 0,02 & 0,001 & 0,00 & 0,001 & 0,00 \\
\hline$\Delta Y \quad(-1)$ & $-2,296$ & 0,00 & $-0,758$ & 0,00 & $-0,625$ & 0,00 \\
\hline$\Delta Y^{*} \quad(-1)$ & 1,841 & 0,42 & $-0,200$ & 0,43 & $-0,037$ & 0,92 \\
\hline$\Delta Y^{B R A}(-1)$ & $-1,012$ & 0,02 & $-0,150$ & 0,00 & $-0,143$ & 0,04 \\
\hline$(-1)$ & $-1,606$ & 0,45 & $-0,574$ & 0,13 & $-0,115$ & 0,86 \\
\hline$\Delta T C \quad(-2)$ & 0,004 & 0,00 & 0,001 & 0,00 & 0,001 & 0,00 \\
\hline$\Delta Y \quad(-2)$ & 2,436 & 0,00 & 0,669 & 0,00 & 0,639 & 0,00 \\
\hline$\Delta Y^{*} \quad(-2)$ & 1,277 & 0,31 & 0,558 & 0,00 & 0,477 & 0,03 \\
\hline$\Delta Y^{B R A}(-2)$ & $-2,454$ & 0,01 & $-0,287$ & 0,00 & $-0,358$ & 0,00 \\
\hline$\Delta E \quad(-2)$ & 1,698 & 0,51 & 0,198 & 0,61 & 0,122 & 0,83 \\
\hline$\Delta T C \quad(-3)$ & 0,001 & 0,04 & 0,000 & 0,00 & 0,000 & 0,02 \\
\hline$\Delta Y \quad(-3)$ & $-0,221$ & 0,54 & $-0,186$ & 0,03 & $-0,190$ & 0,15 \\
\hline$\Delta Y^{*} \quad(-3)$ & 2,595 & 0,10 & 0,222 & 0,23 & 0,420 & 0,17 \\
\hline$\Delta Y^{B R A}(-3)$ & $-0,109$ & 0,84 & 0,068 & 0,36 & 0,029 & 0,78 \\
\hline$\Delta E \quad(-3)$ & $-34,412$ & 0,00 & $-8,342$ & 0,00 & $-7,424$ & 0,00 \\
\hline$\Delta T C \quad(-4)$ & 0,004 & 0,00 & 0,001 & 0,00 & 0,001 & 0,00 \\
\hline$\Delta Y \quad(-4)$ & 0,042 & 0,93 & 0,055 & 0,50 & 0,039 & 0,75 \\
\hline$\Delta Y^{*} \quad(-4)$ & 1,976 & 0,19 & $-0,255$ & 0,12 & $-0,110$ & 0,67 \\
\hline$\Delta Y^{B R A}(-4)$ & $-0,534$ & 0,28 & 0,028 & 0,71 & $-0,038$ & 0,75 \\
\hline$\Delta E \quad(-4)$ & 13,403 & 0,01 & 3,667 & 0,00 & 3,490 & 0,00 \\
\hline
\end{tabular}

33 Modelo com 8 defasagens desconsiderando o nível de significância das variáveis e os critérios de AIC e SIC. 
Tabela A1 (continuação)

\begin{tabular}{|c|c|c|c|c|c|c|c|}
\hline \multirow{2}{*}{\multicolumn{2}{|c|}{ Variável }} & \multicolumn{2}{|r|}{ MQO } & \multicolumn{2}{|r|}{ Poisson } & \multicolumn{2}{|c|}{ Binomial Negativo } \\
\hline & & Coeficiente & P-Valor & Coeficiente & P-Valor & Coeficiente & P-Valor \\
\hline$\Delta T C$ & $(-5)$ & 0,000 & 0,57 & 0,000 & 0,22 & 0,000 & 0,90 \\
\hline$\Delta Y$ & $(-5)$ & $-0,700$ & 0,28 & $-0,299$ & 0,00 & $-0,218$ & 0,07 \\
\hline$\Delta Y^{*}$ & $(-5)$ & $-6,853$ & 0,00 & $-0,617$ & 0,00 & $-0,756$ & 0,01 \\
\hline$\Delta Y^{B R A}$ & $(-5)$ & 1,018 & 0,04 & 0,267 & 0,00 & 0,261 & 0,01 \\
\hline$\Delta E$ & $(-5)$ & $-18,631$ & 0,00 & $-3,550$ & 0,00 & $-3,441$ & 0,00 \\
\hline$\Delta T C$ & $(-6)$ & $-0,002$ & 0,01 & $-0,001$ & 0,00 & 0,000 & 0,00 \\
\hline$\Delta Y$ & $(-6)$ & $-1,848$ & 0,02 & $-0,193$ & 0,03 & $-0,177$ & 0,15 \\
\hline$\Delta Y^{*}$ & $(-6)$ & $-6,145$ & 0,00 & $-0,822$ & 0,00 & $-0,922$ & 0,00 \\
\hline$\Delta Y^{B R A}$ & $(-6)$ & 0,761 & 0,21 & 0,078 & 0,31 & 0,126 & 0,17 \\
\hline$\Delta E$ & $(-6)$ & $-2,990$ & 0,41 & 0,382 & 0,41 & 0,088 & 0,87 \\
\hline$\Delta T C$ & $(-7)$ & $-0,001$ & 0,04 & $-0,001$ & 0,00 & 0,000 & 0,01 \\
\hline$\Delta Y$ & $(-7)$ & 3,088 & 0,00 & 0,689 & 0,00 & 0,613 & 0,00 \\
\hline$\Delta Y^{*}$ & $(-7)$ & 3,754 & 0,02 & 0,553 & 0,00 & 0,373 & 0,23 \\
\hline$\Delta Y^{B R A}$ & $(-7)$ & $-3,236$ & 0,00 & $-0,639$ & 0,00 & $-0,606$ & 0,00 \\
\hline$\Delta E$ & $(-7)$ & $-4,003$ & 0,22 & $-0,714$ & 0,16 & $-0,614$ & 0,20 \\
\hline$\Delta T C$ & $(-8)$ & 0,000 & 0,43 & 0,000 & 0,00 & 0,000 & 0,01 \\
\hline$\Delta Y$ & $(-8)$ & $-2,043$ & 0,00 & $-0,387$ & 0,00 & $-0,358$ & 0,00 \\
\hline$\Delta Y^{*}$ & $(-8)$ & $-0,570$ & 0,68 & $-0,499$ & 0,02 & $-0,239$ & 0,55 \\
\hline$\Delta Y^{B R A}$ & $(-8)$ & $-2,232$ & 0,00 & $-0,440$ & 0,00 & $-0,405$ & 0,00 \\
\hline$\Delta E$ & $(-8)$ & $-6,921$ & 0,06 & 0,298 & 0,62 & $-0,224$ & 0,76 \\
\hline $\mathrm{R}^{2}$ & & & 0,990 & & 0,978 & & 0,949 \\
\hline$R^{2}-A j u$ & ustado & & 0,921 & & 0,817 & & 0,567 \\
\hline SC & & & 4,420 & & 6,680 & & 8,335 \\
\hline $\begin{array}{l}\text { Jarque } \\
\text { (p-valo }\end{array}$ & $\begin{array}{l}\text {-Bera } \\
\text { or) }\end{array}$ & & $\begin{array}{r}1,413 \\
(0,49)\end{array}$ & & $\begin{array}{c}0,412 \\
(0,81)\end{array}$ & & $\begin{array}{l}9,054 \\
(0,01)\end{array}$ \\
\hline Overdi & ispersion & & n.a & & Não & & n.a \\
\hline
\end{tabular}

Nota: 1) n.a - não se aplica; 2) 0 correlograma, que mede a existência de autocorrelação nos resíduos, não identificou este problema em nenhuma das regressões (considerou-se 16 defasagens).

Fonte: Elaboração própria com base no Eviews 5. 